\title{
Las comunidades en la visión de los antropólogos: disquisiciones y lineamientos de análisis
}

\author{
Anthropological View of Communities: \\ Key Elements and Analysis Guidelines
}

\author{
Javier Serrano* (D) https://orcid.org/0000-0003-1265-2893
}

\begin{abstract}
Resumen
El objetivo de este trabajo es caracterizar la visión de los antropólogos acerca de las comunidades y proponer un conjunto de lineamientos útiles para su análisis. Con este fin, se revisan los aspectos fundamentales de la extensa trayectoria antropológica en el estudio de comunidades y se recurre a la propia experiencia etnográfica en comunidades indígenas y campesinas en dos regiones distantes, la Norpatagonia argentina y el occidente de México. Los hallazgos etnográficos respaldan la pertinencia de analizar las comunidades como fenómeno complejo, en términos de proceso y como sistema de relaciones. En este enfoque, las configuraciones comunitarias son consideradas como resultado de procesos históricos pero también como proyecto de futuro. En conclusión, a pesar de su heterogeneidad, dinamismo y complejidad, la visión antropológica sobre las comunidades tiene un sello distintivo vinculado al compromiso empírico que distingue a la disciplina. Sólo a partir de su peculiaridad, la antropología podrá incidir de forma decisiva en los grandes debates actuales sobre comunidades.

Palabras clave: comunidad; visión de los antropólogos; Norpatagonia; occidente de México.
\end{abstract}

\begin{abstract}
The purpose of this paper is to characterize the anthropological view of communities, while proposing a set of guidelines for their analysis. For this, the fundamental aspects of the long anthropological trajectory in community studies are reviewed. At the same time, the own ethnographic experience in indigenous and rural communities in two distant regions, Argentine Norpatagonia and Western Mexico, is used. Ethnographic findings support the relevance of analyzing communities as a complex phenomenon, in terms of process and as a system of relationships. In this approach, community configurations are considered as a result of historical processes but also as projects of future. In conclusion, despite its heterogeneity, dynamism and complexity, the hallmark of the anthropological vision of communities lies essentially in its empirical commitment. Only from its peculiarity can anthropology decisively influence the great current debates about communities.

Keywords: communities; anthropological view; Norpatagonia; Western Mexico.
\end{abstract}

Cómo citar: Serrano, J. (2020). Las comunidades en la visión de los antropólogos: disquisiciones y lineamientos de análisis. región y sociedad, 32, el 248. doi: I0.22 I 98/rys2020/32/ / 248 *Universidad Nacional de Río Negro. Centro Interdisciplinario de Estudios sobre Derechos, Inclusión y Sociedad. Belgrano Núm. 526,
Viedma (8500). Río Negro, Argentina. Correo electrónico: jserrano@unrn.edu.ar

Recibido: 15 de septiembre de 2019

Aceptado: 6 de marzo de 2020

Liberado: 6 de abril de 2020

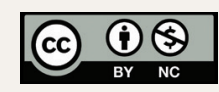

Esta obra está protegida bajo una Licencia

Creative Commons Atribución-No Comercial 4.0 Internacional. 


\section{Introducción}

En las últimas décadas asistimos de nueva cuenta a un intenso debate acerca del concepto de comunidad en el que subyacen, apenas disimuladas, todas las ilusiones muertas de la modernidad (bosquejadas en los siglos XVIII y XIX). En el campo de la filosofía política y en la teoría sociológica las discusiones florecen con un alto nivel especulativo sobre un fondo de añoranza por el sentido de comunidad perdido ante la abrumadora preponderancia de los procesos de individualización y fragmentación propios de la modernidad tardía. De hecho, sería arduo agotar el largo número de autores que intervienen en el debate. Pero algunos de ellos sobresalen por la relevancia y el alcance de sus aportaciones. Así, la obra de Zigmund Bauman (2003 y 2006), quien vincula la problemática de la comunidad al problema de la seguridad (también perdida) en el marco de la modernidad líquida, ha trascendido con mucho el círculo académico y merece citarse. Más ceñidas al ámbito filosófico, cabría mencionar el libro del napolitano Roberto Esposito (2003), Communitas, en el que partiendo del análisis etimológico del vocablo "comunidad" halla que comporta a un tiempo la semántica del don y la de la deuda (el deber de dar), y también las agudas observaciones de Jean-Luc Nancy (2000) a propósito de la comunidad inoperante -sobre estas dos últimas obras, confróntese Groppo (2011)-. Podríamos extendernos en la lista de intervenciones destacadas o incluso controvertidas en las discusiones actuales que se han dado con vehemencia, pero resultaría superfluo en razón de los objetivos de este trabajo. Es oportuno, en cambio, expresar como colofón provisional que, a diferencia de estos autores que operan en un alto nivel de abstracción, los antropólogos se ven en la necesidad de validar sus premisas a la luz del fuerte compromiso empírico que caracteriza a la disciplina; es decir, con mayor frecuencia sus reflexiones vienen vinculadas a la construcción como objetos de estudio de las comunidades particulares que investigan en el terreno. En el presente trabajo se sostiene que este elemento forma parte crucial de lo que podría llamarse la visión de los antropólogos acerca de las comunidades y que de ahí surge la posibilidad concreta de realizar contribuciones disciplinares sustantivas y originales al gran debate. Por otro lado, a la par de profundizar en la visión de los antropólogos, se propone un conjunto de lineamientos útiles para estudiar comunidades en diferentes contextos. Con estos fines, se revisa la extensa trayectoria antropológica en los estudios de comunidad buscando extraer sus elementos fundamentales, al tiempo que se acude a la propia experiencia como etnógrafo en dos regiones muy distantes, la Norpatagonia argentina y el occidente de México. ${ }^{1}$

\footnotetext{
Este trabajo integra diferentes momentos de las tareas del autor como etnógrafo. Las más recientes remiten al estudio de comunidades mapuches en Norpatagonia y han sido financiadas por la Universidad Nacional de Río Negro (UNRN). En relación con el occidente de México, las observaciones remiten de manera primordial a la sierra de Tapalpa, en la cual el autor investigó durante sus estudios doctorales realizados en el Centro de Investigaciones y Estudios Superiores en Antropología Social (CIESAS). En forma complementaria se utilizan observaciones propias y secundarias correspondientes al área purépecha en Michoacán.
} 


\section{De controversias, oposiciones y vitalidad: claves del debate}

Más allá de las distintas tradiciones disciplinares, no es difícil coincidir con el antropólogo Manuel Delgado (2006, p. 39) en que toda disquisición teórica sobre la comunidad debe comenzar por advertir sobre el carácter controvertido del término. En sí misma la palabra “comunidad” entraña desafíos en múltiples sentidos. Su uso ambiguo, polisémico, dúctil y útil en el lenguaje cotidiano es uno de ellos. Del habla corriente se desliza con fluidez a la publicidad, al discurso político y a muchos otros planos. En el ámbito académico -en el cual la precisión conceptual es una pretensión distintiva-, si bien la ambigüedad se reduce, no faltan las discrepancias que coexisten a la vez en disenso y sin que ninguna logre imponerse. $Y$ es que hay distintas formas de entender 0 interpretar el concepto bajo diferentes perspectivas o aproximaciones teóricas. No obstante, en lo que podría postularse como una instancia persistente del debate, el denominador común es la incesante reflexión sobre las propuestas originales de los autores clásicos del pensamiento sociológico, a saber, Weber, Durkheim, Marx y el precursor Tönnies (véase De Marinis, 2012). En la teoría social todo se funda en una vieja oposición decimonónica que suele considerarse alternativamente como vigente y anacrónica. En un contexto de continuos cuestionamientos y constantes menciones, la dicotomía primigenia entre comunidad y sociedad planteada por Tönnies en las postrimerías del siglo XIX no parece haber sido rebasada; mantiene hoy -aunque no siempre de manera explícita - la vertebralidad que en su momento le reconociera Nisbet (2003) para la etapa clásica del pensamiento sociológico (véase Honneth, 1999). A la par, las posiciones comunitaristas arraigadas en Aristóteles de Estagira y las posturas contractualistas apoyadas en Hobbes de Malmesbury -muchos siglos los separan - atraviesan todo el debate renovando viejas controversias de la filosofía política a través de argumentos remozados que aseguran una disputa continua y en esencia inconclusa. El corazón de las discusiones está atrapado en estas contraposiciones binarias que han probado ser fecundas en la teoría (otras dicotomías enlazadas a éstas las secundan), aunque padecen todas las desventajas y limitaciones propias de los esquemas conceptuales dicotómicos que reducen la complejidad del fenómeno. En cualquier caso, la trascendencia y la vitalidad del debate con sus distintas aristas son innegables y sus efectos son palmarios en los ámbitos jurídico y político, tanto en los Estados nacionales como en organizaciones de nivel internacional.

El núcleo más resonante en las discusiones contemporáneas, sin embargo, retoma escasa o sólo de manera parcial la larga trayectoria de reflexiones y estudios de caso sobre comunidades propios de la antropología (como también de la historia y de otras disciplinas). Por un lado, en el alto nivel de abstracción en que se llevan las argumentaciones se recurre a ejemplos ilustrativos paradigmáticos (sin duda ad hoc) que tienen como contrapartida un desdén poco solapado por los estudios empíricos concretos que podrían convalidar o no sus resultados. Al parecer, prevalece una infundada reticencia a reflexionar sobre los materiales empíricos provistos por los estudios de comunidad etnográficos, que han tendido a enfocarse en primer lugar en contextos rurales (aunque no 
tardaron en aplicarse en espacios citadinos), como también por los desarrollos de la psicología comunitarista que, a través del concepto de sentido de comunidad (Sarason, 1973; McMillan y Chavis, 1986), se han centrado en áreas urbanas. ${ }^{2}$ Por otro lado, el sentido mismo del debate más álgido trasluce una íntima preocupación por el colapso de las identidades comunitarias en la modernidad postrera y la búsqueda desesperada de re-constituirlas como una alternativa ante las calamidades ya insoportables del individualismo tardomoderno. Las reflexiones sobre las comunidades indígenas y campesinas latinoamericanas que los antropólogos estudiaron con profusión desde principios del siglo XX, han quedado innecesariamente relegadas en el debate. Pensando en la lógica de Bauman (2003), este tipo de comunidades que probaron con tenacidad ser persistentes a pesar de los permanentes augurios de su inminente desaparición, no pueden ser descritas en términos de liquidez. De ahí que Díaz Polanco (2015, pp. 29-32) reproche al autor el haber reducido de manera arbitraria el análisis de los procesos comunitarios a los contextos de desintegración e integración líquida de nuevas comunidades características de la tardomodernidad, haciendo caso omiso de la perdurabilidad y vigencia de las comunidades preexistentes que a menudo observamos en América Latina. En consecuencia, problemas de enorme relevancia teórica, tales como la persistencia o adaptabilidad de este tipo de comunidades que de manera habitual han sido englobadas bajo el rótulo de tradicionales, sólo ocupan un lugar marginal en el debate. Con toda probabilidad, esta manifiesta limitación se vincula a la porfiada eficacia de la añeja oposición tradición/modernidad (correlato del par comunidad/sociedad) que involucra presupuestos de progresión histórica en que, por definición, las comunidades tradicionales están emplazadas en el pasado -o son sus resabios- y destinadas a desaparecer ante el paso arrollador del impulso civilizatorio. Y así, la reflexión sobre las comunidades indígenas y campesinas, que fueran objeto de estudio privilegiado de los antropólogos, no alimenta suficientemente las grandes disquisiciones teóricas actuales.

\section{Las comunidades en la visión de los antropólogos}

La antropología, por su parte, lucha con sus propios demonios y no es un escenario de enfoques acríticos en concordia: su evolución en torno a la problemática de las comunidades ha sido compleja y dinámica. En particular, se ha objetado que los copiosos estudios de comunidad plasmados por los antropólogos desde las primeras décadas del siglo XX tenían una fuerte impronta descriptiva que redundaba en el menoscabo del desarrollo teórico (Crow y Allan, 1994). Pero sin duda tal afirmación debe ser matizada y examinada a la luz de diferentes momentos, perspectivas y áreas de estudio, en la muy rica tradición antropológica en la materia. Baste mencionar por ahora el célebre continuum folk-urbano esgrimido por Robert Redfield (1941), un principio clave que encausó los primeros estudios de comunidad y que tuviera una decisiva influencia en las ideas sobre modernización en América Latina, aunque no tardó en ser impugnado en

2 No hay por supuesto una división de trabajo estricta. 
el marco de la incisiva polémica - también célebre- que se desatara con el reestudio de Tepoztlán por parte de Oscar Lewis (1951; Gorilek, 2008). Su legado, sin embargo, es aún reconocible y quizá haya hecho una contribución mayor a la generalizada imagen de pequeñas comunidades rurales armoniosas, detenidas en el tiempo, autosuficientes y atrapadas en la tradición (Redfield, 1955). ${ }^{3}$ Por otro lado, al interior de la disciplina no tardaron en surgir agrios cuestionamientos a la corriente culturalista -en México la palabra llegó a convertirse en agravio- que había dominado aquellos primeros estudios. Sobre la piedra basal de los estudios de cultura y personalidad desarrollados en la antropología americana, el enfoque culturalista se centraba en la naturaleza de los vínculos entre los miembros de la comunidad enfatizando elementos psicosociológicos (Gossiaux, 1996), en franco desmedro de los procesos históricos y de la situación de clase. Se bosquejaban así, a contramano de las perspectivas históricas, según se aducía, comunidades despojadas de historia y de relaciones económicas estructurales, de modo que se presentaba a los comuneros como los virtuales responsables de su propia pobreza y marginalidad. Hoy resulta claro que aunque ambas posiciones parecían ser irreconciliables, de ninguna manera eran mutuamente excluyentes. A su vez, si bien los antropólogos pronto rechazaron la somnolienta imagen que proveían las primeras etnografías de comunidad, continuaron orientando gran parte de sus esfuerzos a estudios en pequeñas comunidades - aún lo hacen- bajo diferentes aproximaciones conceptuales pero con una inquebrantable vocación empírica.

Hacia mediados del siglo XX la comunidad se presentaba como un elemento medular en relación con problemáticas centrales en la disciplina, entre las que cabe destacar tres por su particular importancia: a) la comprensión del mundo campesino - pensemos en los trabajos clásicos de Eric Wolf (1955, 1957 y 1990) acerca de la comunidad corporada-; b) los procesos migratorios internos e internacionales que desafiaban de continuo las definiciones de comunidad -podemos ejemplificar aquí con la obra del propio Oscar Lewis (1951)-; y c) la cuestión capital, monopolizada por los antropólogos, de los procesos de re-producción de las identidades indígenas en los que la comunidad tenía un manifiesto papel central. Entre tanto, cuando los antropólogos se veían en la necesidad de conjeturar una definición de comunidad, con frecuencia recurrían al terreno seguro de los clásicos citando a menudo a Max Weber, por ejemplo, Brow (1990). ${ }^{4}$ Así las cosas, en la década de 1980 los enfoques simbólicos vinieron a conmover las concepciones usuales de comunidad. En 1983 aparece el influyente libro de Benedict Anderson (1991) acerca de las comunidades imaginadas, mismo que con gran efectividad y no sin audacia desplazó el concepto hacia el análisis de las nacionalidades. Si hasta entonces el lugar, entendido como espacio físico, era consustancial a las distintas formas de entender la comunidad, al ser concebidas como imaginadas las comunidades comenzaron

3 Por su puesto, la literatura y luego el cine han tenido un papel decisivo en ello.

4 De Marinis (2010) ha venido a problematizar la concepción de Weber, en apariencia monolítica, retomada de Economía y sociedad. Analizando el conjunto de la obra weberiana, el autor encuentra profundas ambivalencias acerca de la comunidad, ya que es posible distinguirla como antecedente histórico, tipo ideal e incluso proyección utópica. 
a pensarse en términos metafísicos, generando, más allá de los indiscutibles aportes de este libro, entuertos conceptuales que aún persisten (Blackshaw, 2010, p. 6). ${ }^{5}$ Pero la corriente era irreversible y poco después se publica The Symbolic Construction of Community de Anthony Cohen (1985), ${ }^{6}$ que retoma la prístina herencia de los planteamientos de Fredrik Barth (1976) acerca de los grupos étnicos y sus fronteras. Mientras que los símbolos habían sido utilizados con frecuencia para la descripción de las comunidades - fiestas, rituales, costumbres, giros lingüísticos, etcétera-, Cohen llevó la discusión al hecho de que los símbolos eran elementos constitutivos fundamentales en cualquier comunidad y que su importancia se revelaba en los procesos de distinción y delimitación respecto de otras comunidades y niveles identitarios. Por entonces la cuestión de la pertenencia y la problemática de la identidad, que asomaba ya como uno de los temas torales en la disciplina - aunque de alguna manera era una nueva etiqueta para un viejo tema (Giménez, 1997)-, se convirtieron en lugar común en los estudios etnográficos de comunidad. Un poco más adelante, los estudios migratorios que a la sazón tenían un intenso desarrollo, provocaron planteamientos que obligaron de nueva cuenta a repensar el problema del lugar. La comunidad había sido, y aún es, una unidad de análisis primordial en las investigaciones sobre migración; pero en la década de 1990 surge la perspectiva del trasnacionalismo, formulada en primer término por Rouse (1991) y Basch, Glick Schiller y Szanton Blanc (1994), que llevó a los migrantólogos (muchos de ellos antropólogos) a replantear la conceptualización de las configuraciones comunitarias, llegando incluso a proponer el concepto de comunidades transnacionales (Portes, 1997; Serrano, 2002, pp. 14-19) y a acudir, incluso, a la polémica concepción de desterritorialización. ${ }^{7}$ Más allá de las controversias, la nueva propuesta terminó de corroer la perenne imagen de la comunidad bien localizada y sustancialmente afincada al territorio. Como nunca antes, se tornó evidente la tensión inherente a la concepción más inmediata de comunidad, aquella que remite por una parte a un modo de vivir en sociedad y por otra a un territorio “constituido por la impronta humana” (Lisbona Guillén, 2006, p. 25). Y así, entrando al nuevo milenio, la comunidad persistió como tema de primer orden entre los antropólogos, siempre bajo una variedad de enfoques, con distinto peso de acuerdo con epistemologías nacionales y áreas de estudio, como también en relación con diferentes problemáticas y líneas de investigación. $L a$ comunidad a debate, libro editado por Lisbona Guillén (2006), da una buena idea de esa vigencia y heterogeneidad en el campo de la antropología para el contexto mesoamericano.

El repaso a grandes trazos, por necesidad incompleto, que se ha bosquejado en los párrafos previos, busca acercar al lector aspectos fundamentales de la

5 Anderson (1991, p. 6) resaltó que "all communities larger than primordial villages (and perhaps even these) are imagined". Para los antropólogos la aclaración entre paréntesis resulta ociosa. En sentido estricto, todas las comunidades son imaginadas, incluyendo aquéllas donde prevalecen los encuentros cotidianos y las relaciones cara a cara.

6 En este mismo camino, tiempo después aparece Imaginary Communities de Philip Wegner (2002), que no se discutirá aquí. Blackshaw $(2010$, p. 6) anotó que hacia finales del siglo XX se produce una revolución conceptual en la que la comunidad se tornó inmaterial, "fantasmagórica".

7 Para una revisión penetrante del concepto de desterritorialización, véase Haesbaert (2011). 
visión de los antropólogos acerca de las comunidades sin avasallar su complejidad, heterogeneidad y dinamismo. Se continuará ahora abonando este camino, pero encarando esta vez el objetivo subsidiario de retomar aspectos específicos de la tradición antropológica para proponer una serie de lineamientos que luego puedan resultar de utilidad para el análisis de comunidades en muy distintos campos disciplinares. Con este propósito se apelará a la vasta trayectoria teórica y empírica desarrollada en México en la materia y, como se ha anticipado, se acudirá a ejemplos del occidente mexicano ${ }^{8}$ y de la Norpatagonia argentina, refiriendo casos etnográficos de cosecha propia que remiten a contextos indígenas y campesinos. Las reflexiones vienen teñidas por estos contextos, pero la propuesta que aquí se ofrece no se limita a ellos. El planteamiento se organiza en tres ejes: a) la comunidad como problema, b) como proceso, y c) como sistema de relaciones. El esquema contempla un cuarto eje que, dada su densidad y complejidad, no se discutirá en esta ocasión; remite a las comunidades como totalidades, examinándolas como conjuntos humanos holísticos, en los que rige el viejo adagio de que el todo es más que la suma de las partes. En todo caso, estos ejes reflejan distinciones analíticas, y de hecho están muy interrelacionados; en conjunto comportan un modo - de ninguna manera el único- de examinar y pensar la comunidad, y sólo después un esquema analítico. En esta perspectiva la comunidad es siempre un problema y un reto de investigación.

\section{La comunidad como problema, proceso y sistema de relaciones}

La comunidad como problema

En líneas generales, los antropólogos han considerado la comunidad indígena mesoamericana como una unidad de análisis clave, referida a la estructura social indígena básica de nivel supra familiar (Zolla y Zolla, 2004). De hecho, la comunidad se convirtió "no sólo en la unidad espacial, social y cultural más adecuada para observar y conocer al indio, sino además, en la unidad capaz de definirlo" (Aguirre Beltrán, 1990, p. 291). ${ }^{9}$ La atención se puso en los lazos de parentesco, que suelen explicar buena parte de la organización comunitaria, y en las redes sociales, a menudo densas, compuestas por relaciones multiplejas, ${ }^{10}$ así como en aspectos normativos que dan lugar -en principio- a vínculos solidarios y de apoyo mutuo. ${ }^{11}$ El parentesco y el territorio se presentan como dos elementos fundamentales. No sin ingenio Aguirre Beltrán y Pozas Arciniega

8 En 2018 el autor del presente artículo realizó una estancia de investigación en el Centro de Investigaciones en Geografía Ambiental (CIGA) perteneciente a la Universidad Nacional Autónoma de México (UNAM), emplazado en la ciudad de Morelia. Tuvo entonces la oportunidad de familiarizarse con el contexto purépecha y utilizará también parte de esa experiencia junto con la más extensa en la sierra de Tapalpa.

9 En 1948, en una definición fundacional para el indigenismo, Alfonso Caso sostuvo que "es indio el que se siente pertenecer a una comunidad indígena" (Caso, 1996, p. 337).

10 Por oposición a las relaciones simples, según la famosa formulación de Max Gluckman.

11 Se ha señalado que el énfasis en la importancia de las relaciones y la solidaridad comunitarias suele ser exagerado (Blackshaw, 2010, p. 9). 
(1981) afirmaron que la comunidad indígena "no es otra cosa que una familia extensísima que ocupa un más o menos dilatado territorio” (p. 26). El espacio, sin embargo, constituye un elemento primordial, ya que las comunidades indígenas remiten en esencia a conjuntos de personas interrelacionadas entre sí a propósito del territorio. Las comunidades mapuches que se estudiaron en la llamada Línea Sur rionegrina en la Norpatagonia, una vasta zona rural, constituyen excelentes muestras de ello. Sin embargo, veremos más adelante que es necesario matizar la aseveración precedente, con vista en el notable caso de las comunidades indígenas citadinas que indagamos en el Valle Inferior del río Negro y que en lo fundamental se apartan de lo dicho. No obstante, es con base en el territorio, entendido ya como espacio socialmente apropiado (Giménez, 2001), y a partir de un complejo simbólico que abarca rituales, giros lingüísticos, costumbres propias, entre otras cosas, que desde muy temprano los miembros de la comunidad desarrollan un poderoso sentido de identificación comunitaria. Y a la vez la comunidad desempeña un papel fundamental en la reproducción de las identificaciones étnicas ya que, siguiendo a Warman (2003), "la mayoría de los indígenas mexicanos finca su identidad étnica primaria en su comunidad" (p. 19). Por otro lado, las comunidades resultan de la historia. A menudo padecen distintos tipos de conflictos al tiempo que se insertan en sistemas sociales, económicos, políticos y geográficos más amplios -el municipio, el estado, la región-; es decir, participan en una serie de relaciones que explican su existencia. Más allá de los enfoques teóricos específicos, cuando los antropólogos abordan una comunidad, tanto en el área mesoamericana como en la Norpatagonia, lo hacen con estos elementos generales en mente, y sobre esta base persiguen los objetivos concretos de cada investigación. Con todo, existen otras muchas formas de abordar las comunidades como objeto de estudio o intervención. En una buena cantidad de investigaciones de la más diversa índole prevalece lo que podríamos llamar una aproximación instrumental, inmediata, o incluso intuitiva a la comunidad. Esto es, se la aborda como dato irreductible de la realidad, siendo con frecuencia asimilada a alguna localidad específica (de hecho, comunidad y localidad suelen ser sinónimos en el lenguaje cotidiano). En otras palabras, se la considera como una unidad de análisis autoevidente y en consecuencia se la asume como una entidad monolítica, eventualmente homogénea. Por supuesto, dependiendo de la naturaleza de la investigación, en algunos casos esto no implica un desacierto tan grave. Pero la mayor parte de las investigaciones requieren -contra la operación reduccionista-considerar la comunidad como un fenómeno complejo que no puede determinarse de antemano, mientras que su traducción en unidad de análisis es en concreto una construcción del investigador. En la perspectiva antropológica la comunidad es siempre un problema y objeto en construcción, antes que un dato dado de la realidad. Los niveles y alcances de la problematización en cada caso son estricta responsabilidad del antropólogo.

Si la comunidad como problema es una elaboración del investigador, los elementos que componen el problema surgen tanto del fenómeno mismo como de su conceptualización. Se trata de una construcción laboriosa y en constante revisión que invariablemente atraviesa dificultades. Una muy frecuente remite 
a la polisemia y a la ambigüedad que conllevan el uso corriente del término comunidad en los distintos referentes empíricos. Aunque no pueden obviarse, retomar sin más las categorías cotidianas conduce a errores; el investigador deberá conocer los diferentes usos antes de dirimir el que conviene a su unidad de análisis. En todos los casos las comunidades tienen nombre propio distintivo, una obviedad que no carece de importancia. El seguimiento de los nombres propios a escala local - pueblos, barrios, rancherías o parajes- puede servir de guía preliminar para definir la unidad y los diferentes niveles de análisis. Como es sabido, buena parte de los pueblos y de las comunidades indígenas en México tiene un nombre propio que consiste en la añadidura del nombre de un santo patrono católico a un topónimo en lengua indígena. Pronto se tratará aquí de San Antonio de Tapalpa, que es ejemplo de ello. Por otro lado, la expresión “comunidad indígena” conlleva una carga semántica paradójica que constituye un problema en sí misma. En efecto, el concepto de comunidad no es de origen indígena, sino que pertenece a la tradición intelectual occidental, y lo mismo sucede con el concepto de indígena: ambas son categorías exógenas a la entidad que se pretende definir. Indígena y su versión coloquial indio son términos bastante problemáticos, porque aluden a una categoría supra-étnica del orden colonial (Bonfil Batalla, 1995) que arrastra una densa cadena de prejuicios afianzados en el sentido común. Siendo una categoría pluriétnica, no designa ninguna identidad étnica en particular; no puede hacerlo, sino que se define como dimensión identitaria - racializada y estructurada en relaciones de poder (Quijano, 2000)- por oposición al conquistador europeo. De allí su anclaje en el orden colonial. Así configurada, la categoría indígena abarca una enorme diversidad de identificaciones étnicas en esencia disimiles. Algo análogo sucede con la expresión "comunidades indígenas", ya que agrupa una gran variedad de configuraciones que tal vez tengan más diferencias significativas que semejanzas elocuentes entre sí. Más allá de estas consideraciones, en cada caso es el investigador quien, de acuerdo con sus objetivos de investigación, decide cuáles serán los elementos que componen la comunidad como problema, lo que necesariamente entraña una concepción de comunidad que debe explicitarse y que en sí misma forma parte del problema. Pensar la comunidad como proceso contribuye a ello.

\section{La comunidad como proceso}

Uno de los aspectos en que la investigación etnográfica puede gravitar en relación con los grandes debates se refiere a la concepción evolutiva implícita en la trillada oposición comunidad/sociedad, la cual viene vinculada con los persistentes pares tradición/modernidad y rural/urbano. ${ }^{12}$ La hipótesis subyacente, tomada en ocasiones como verdad revelada, asume que la comunidad tradicional rural cederá definitivamente, en virtud de una progresión irreversible, ante la sociedad urbana moderna. El continuum folk-urbano al que ya nos hemos referido constituye un buen ejemplo. En dicha concepción las comunidades

12 Sólo con dificultad se podrá eludir el uso de estas oposiciones. El lector avezado advertirá que se utilizan en este trabajo, lo que no implica una aplicación acrítica de ellas. 
pertenecen al pasado y lo que se observa en el presente no es otra cosa que la reminiscencia de ese pasado, mientras que el futuro, en virtud del progreso irrevocable, corresponde a la sociedad moderna, en su mayoría urbana. Desde esta visión, las comunidades indígenas, premodernas y rurales por axioma, más tarde o más temprano habrán de desaparecer. Pues bien, esto puede ponerse a prueba en el terreno a través de la observación etnográfica. ¿Están en verdad desapareciendo las comunidades indígenas y campesinas? ¿Sólo están resistiendo y postergando el final inminente? ¿En verdad pertenecen al pasado? ¿No tienen futuro? Responder estas preguntas equivale a establecer diagnósticos y evaluar procesos. Un conjunto de trabajos de base etnográfica, así como la propia experiencia de investigación, sugieren que la persistencia de las comunidades indígenas se entiende mejor en términos de adaptabilidad y que de ninguna manera se pueden considerar meros resabios estancos del pasado. Los estudios de Zárate Hernández (2011) y de Garibay Orozco (2008), por ejemplo, muestran el peculiar dinamismo y vitalidad de algunas comunidades indígenas en el sur y en el occidente de México, incluyendo importantes ajustes y trasformaciones en el plano ideológico, es decir, en aquello que por definición se considera más estable. Garibay Orozco (2008) muestra cómo, en un contexto generalizado de quebranto de la economía campesina, algunas comunidades indígenas con recursos forestales han desarrollado firmes ideologías comunalistas que, sin incongruencia, dan lugar a verdaderas empresas colectivas consagradas a la explotación industrial de los bosques. Esto les permite incluso cierta pujanza a partir de una decisiva inserción en la economía de mercado capitalista. De acuerdo con el autor, este tipo de organización basada en el comunalismo engarza de lleno con el capitalismo y desplaza la familia campesina como centro de la reproducción social en las comunidades indígenas, lo cual evidencia su virtual dinamismo. Por su parte, Zárate Hernández (2011) propone entender la nítida vigencia actual del comunalismo en la meseta purépecha, en el marco de una variedad de estrategias que tienen como antecedente fundamental la emergencia del "indígena moderno" - una aparente contradicción de términos-, sujeto histórico que conjuga valores colectivos con algunos elementos del credo liberal. En ambos casos, partiendo del registro etnográfico se detallan procesos de ajuste a condiciones desfavorables que escapan al control de la comunidad y que expresan disposición para el cambio y capacidad de adaptación; ${ }^{13}$ con seguridad, procesos como éstos no siempre serán exitosos. En todo caso, pensar las comunidades en términos de adaptabilidad conlleva una hipótesis alterna y superadora de esquemas de progreso o evolutivos, hipótesis que permite explicar una gama de situaciones que van, dependiendo de una variedad de factores entre los que sin duda figura la disponibilidad de recursos, de la franca desarticulación de algunas comunidades (que no logran adaptarse) hasta la regeneración o reafirmación concreta de las configuraciones comunitarias en escenarios de desventaja. La premisa fundamental aquí es que las comunidades constituyen fenómenos dinámicos, cambiantes, en permanente trasformación,

13 El término adaptación incluye polémicas que no se pueden desarrollar aquí. Algunos autores prefieren hablar de resistencia e incluso de sobrevivencia (Boccara, 2002). Siendo enfoques distintos en principio, no se excluyen entre sí. 
de final abierto (lo que no implica que no estén sujetas a fuertes presiones y que tal vez algunas de ellas terminen por desaparecer). Se cuestiona así la supuesta inmutabilidad o estabilidad y la propensión a la tradición de las comunidades. En todo caso, en esta instancia la palabra clave es proceso, lo que entraña en sí una consideración fundamental sobre el tiempo.

\section{Productos históricos}

En lo que respecta al tiempo, las comunidades tienen, por así decirlo, una triple existencia. Por un lado, existen en un momento determinado, que puede ser el presente, se originan en procesos históricos que remiten al pasado y se proyectan al futuro. Algunas investigaciones se limitan, con sensatez, a recortes acotados del tiempo; por ejemplo, cuando se indaga la demografía de una comunidad en un periodo específico. Este tipo de análisis, oportuno en muchos casos, congela la comunidad, la detiene en el tiempo, y el riesgo es perder de vista que se trata de fenómenos en proceso. En cambio, es muy frecuente la situación en que se aborda el pasado de la comunidad en la medida en que lo requieren los objetivos de investigación. La explicación genética es un recurso habitual y en ella se recurre al pasado para dar cuenta de las condiciones que dieron lugar a aquello que se pretende explicar. Una buena cantidad de estudios se ajusta a esta modalidad y, en particular, no hay antropólogo que no revise los antecedentes de su problema de investigación. Pero un aspecto fundamental, que hay que destacar aquí, alude a la concepción misma de comunidad y se refiere a que ellas son productos históricos. Concebir las comunidades de esta manera conlleva una mirada particular que incide en el proceso de investigación. Muchas de las comunidades indígenas de México, en la meseta purépecha por ejemplo, parecen estar allí desde siempre y suelen ser caracterizadas como ancestrales -término cuando menos problemático-; parecería que sus orígenes se pierden en un pasado remoto e inaccesible. Sin embargo, en su gran mayoría las comunidades que hoy observamos, con su fidelidad a los sistemas de cargo y su disposición en torno al templo, son manifiesto resultado de la época colonial (Paredes Martínez, 2017). En contraste, las comunidades mapuches que se observan en la Norpatagonia argentina y que también suelen describirse como ancestrales, se originan notoriamente con posterioridad a las campañas militares de la llamada Conquista del Desierto - un manifiesto eufemismo, ya que a la sazón el desierto estaba poblado por distintos grupos indígenas- en las últimas décadas del siglo XIX, es decir, en pleno periodo republicano. Considerada primero como gesta y luego como genocidio (Serrano, 2020a), la Conquista implicó una drástica ruptura del orden previo y la reorganización ulterior de la población indígena, tanto en términos sociales como espaciales. Más allá de las nítidas diferencias, en ambos casos es posible concebir las comunidades indígenas como resultado de procesos de dominación -colonial en un caso, republicana en el otro- que establecieron asimetrías perdurables fundamentales bajo una estrategia de control de la población indígena, lo que con frecuencia implicaba su congregación y reubicación geográfica, así como una redefinición del espacio en la lógica administrativa (Díaz Polanco, 1995, p. 236). En suma, 
cualquiera que sea el tipo de comunidad de que se trate, las comunidades son siempre producto de la historia y esa historia define aspectos elementales de las comunidades que hoy atestiguamos. Dicho de otro modo, las configuraciones comunitarias no son entidades naturales; son creación y resultado de procesos históricos.

Proyectos de futuro

En muchas comunidades indígenas actuales, el tiempo lineal, que destruye el pasado a cada instante, convive con cosmovisiones que involucran una concepción cíclica del tiempo. Esta concepción alterna suele expresarse en rituales de renovación, como puede ser el we tripantu entre los mapuches de la Norpatagonia y las celebraciones del fuego nuevo entre los purépechas del occidente de México. En esta concepción, el pasado no desaparece, sino que se renueva sin cesar de acuerdo con los ritmos estacionales de la naturaleza. Insertas en esta lógica, las comunidades indígenas se regeneran de manera periódica, lo cual, de algún modo conlleva su proyección hacia el futuro. En el transcurso de la vida cotidiana prevalece entre los comunitarios indígenas la sensación de que la comunidad se extiende desde siempre y para siempre. Con esta sensación, la comunidad trasciende a los individuos que por accidente la conforman: existía desde antes del nacimiento y existirá luego de la muerte personal de cada uno de sus miembros (quizá pasarán a formar parte entonces de la comunidad de los ancestros). Todo esto se experimenta con naturalidad y apenas llega a formularse en palabras o siquiera en instancia consciente. Se le contraponen la sensación de presente continuo y la perspectiva agonística que caracterizan la tradición occidental, donde todo empieza y acaba en el individuo mismo. Sin embargo, en algunos casos la comunidad indígena se explica no como entidad histórica afianzada, sino en esencia como objeto en el futuro, como meta a alcanzar e instancia en construcción. Es decir, se entiende mejor como proceso constructivo y proyecto de futuro que convoca y aglutina de manera provisional lazos comunitarios antes que como entidad consolidada. Tal es el caso de las nuevas comunidades mapuche y mapuche-tehuelche que estudiamos en las ciudades y áreas aledañas del Valle Inferior del río Negro, en la provincia patagónica homónima. Pensamos que sus características se ajustan a las de muchas otras configuraciones comunitarias indígenas en contextos citadinos. Se trata de un puñado de comunidades cuyos orígenes se remontan a la década de 1980 en las ciudades de Viedma y Carmen de Patagones, emplazadas en la zona atlántica de la Norpatagonia. Sólo por esta razón las llamamos nuevas, aunque el término es algo equívoco. Su emergencia se explica en el contexto de la transición democrática en Argentina, un contexto propicio para la visibilización y la revitalización de las identificaciones indígenas que, por otra parte, a la sazón estaban re-emergiendo a nivel mundial. En tal marco se fueron generando en estas ciudades diversas formas de organización indígena que antecedieron a la conformación de comunidades que comenzaron a distinguirse con nombre propio. Su peculiaridad reside en que carecen de orígenes ancestrales o míticos y en que no poseen territorio ni aspiran a él. Por este motivo están someti- 
das a una doble impugnación de legitimidad: por parte de quienes provienen de comunidades tradicionales y cuestionan la imposibilidad de comunidades sin territorio, y por parte de los sectores recalcitrantes de la sociedad local que acusa a sus miembros de ser falsos indígenas, ya que en su interpretación esencialista los verdaderos indígenas sólo existen en el pasado o en las áreas rurales. Aun así, estas comunidades indígenas citadinas ponen en práctica su derecho a existir como tales. De acuerdo con nuestro análisis, lo típico es que estén conformadas por inmigrantes urbanos de segunda generación (y subsiguientes) de origen primario diverso, pero casi siempre rural. No se organizan en torno al territorio ni tienen un pasado remoto compartido; la membrecía no está determinada por el parentesco y no es espontánea, sino voluntaria y revocable, mientras que el proceso constructivo involucra discursos elaborados y prácticas conscientes de carácter programático. Al carecer de un pasado comunitario de referencia, la comunidad se orienta hacia el futuro compartido en clave indígena. En términos generales, se observa que los esfuerzos puestos en la construcción de estas comunidades tienen un papel fundamental en la re-producción de las identificaciones indígenas en contextos citadinos (Serrano, 2020b). De manera consciente o no, con o sin territorio ni pasado común, en ámbitos rurales y urbanos, ya sea como proyección indefinida o programática, todas las comunidades se proyectan al futuro. Desde la perspectiva etnográfica, se trata de una dimensión del fenómeno que siempre se debe explorar y que, en algunos casos, como el que se acaba de referir, resulta una instancia de análisis ineludible.

\section{La comunidad como sistema de relaciones}

Hay por lo menos dos requisitos indispensables en la conformación de las comunidades: a) el sentido de pertenencia a una comunidad y b) una serie de relaciones sociales efectivas que dan lugar a la configuración comunitaria. Podríamos afirmar entonces que la comunidad se realiza, por una parte, como fenómeno subjetivo y, por otra, como conjunto de relaciones objetivas. En primer lugar, desde el punto de vista de las relaciones, las comunidades tienen fronteras y a la vez son sistemas abiertos. Siguiendo aquí a Cohen (1985), la construcción de la comunidad es un fenómeno simbólico que estriba en el trazado de fronteras de membrecía. Forjadas en largos procesos de interacción al punto der ser reconocidas por propios y extraños, estas fronteras distinguen a los miembros de la comunidad respecto de quienes no lo son. En otras palabras, diferencian un nosotros comunitario respecto de otros. La existencia misma de cada comunidad depende del proceso de delimitación simbólica, mientras que la demarcación expresa una instancia relacional que opera por contraste, deslindando a la comunidad respecto de otras entidades sociales del mismo u otro orden. La distinguibilidad se produce a través de un complejo de rasgos culturales distintivos (Giménez, 1997), a partir de los cuales se construye la identificación comunitaria. ${ }^{14}$ De esta manera, la comunidad se inscribe en una

14 Para evitar cualquier interpretación esencialista, cabe aclarar que este complejo de rasgos no es estático sino dinámico, en esencia mutable. Lo que perdura, parafraseando a Barth, cuya huella es ostensible en este planteamiento, son las fronteras de distinguibilidad. 
trama de relaciones de distinguibilidad históricamente conformada. Las fronteras identitarias constituyen el primer elemento que se desea destacar aquí con referencia a la comunidad como sistema de relaciones. De inmediato hay que señalar que, observadas en el terreno, en una variedad de situaciones las fronteras pueden ser menos claras de lo que sugiere la propuesta teórica.

En el pueblo de Tapalpa, ubicado en la sierra homónima hacia el sur de Jalisco, en el cual el autor del presente trabajo hizo etnografía por varios años (Serrano, 2002 y 2006) y que aún visita, aunque con intermitencias, la palabra comunidad se usa en varios sentidos. En ocasiones abarca a los habitantes del pueblo mismo junto con los de las distintas localidades y rancherías que forman parte del municipio homónimo, o, en estricto, de la parroquia local. ${ }^{15} \mathrm{La}$ unicidad comunitaria de este sistema heterogéneo se manifiesta con palmaria claridad en las fiestas patronales dedicadas a la Virgen de Guadalupe. Organizadas en novenario, las celebraciones contemplan un día específico para la peregrinación de las poblaciones rurales, como también para la de los distintos barrios del pueblo cabecera. En el día asignado las personas oriundas de una ranchería determinada, por ejemplo, peregrinarán hacia el templo principal del pueblo portando insignias distintivas, que incluyen el nombre propio de la localidad particular. Se hace patente así tanto su carácter de entidad diferenciada como su inclusión en la comunidad parroquial mayor. En otras ocasiones, el uso coloquial local de la expresión “comunidades" designa las rancherías y los parajes rurales que forman parte del municipio, y tienen como contraparte el pueblo cabecera que se presenta como unidad diferente delimitada por rígidas fronteras simbólicas. Estas fronteras operan como diferenciación respecto de las rancherías ${ }^{16}$ y también de las ciudades, en particular Guadalajara, que es el referente urbano más significativo. Ciudades y rancherías son vistas como amenaza al reservorio moral de raigambre católica que al parecer impera entre los habitantes de la cabecera. El pueblo está simbólicamente cercado por cruces situadas en alturas y puntos estratégicos; cada una tiene nombre propio y posee narrativas asociadas. Están firmemente enclavadas en el imaginario local. Estas cruces definen el espacio en términos simbólicos, circunscribiendo el pueblo de Tapalpa como recinto meritorio y sagrado de los pueblerinos. Más allá de los límites demarcados por las cruces, habitan los otros, personas que forman parte de distintas entidades sociales, rurales y urbanas, que contrastan con la propia y que en principio suponen para los tapalpenses un peligro latente de degradación moral y desamparo. Por esta misma razón, a los migrantes oriundos del pueblo, por haber trasgredido el cerco, son puestos bajo tela de juicio, aunque difícilmente llegan a ser expulsados de la comunidad por ello (Serrano, 2002). Habiendo diferentes alternativas, ¿cómo dirimir entonces cuál es la verdadera comunidad tapalpense?

15 El pueblo mismo de Tapalpa no puede ser caracterizado en estricto o a priori como indígena o campesino, lo que no impide aplicar el modelo de análisis que se propone aquí, ya que la categoría misma y el sentido de comunidad son habituales en este contexto.

16 Trevor Stack (2012) realizó una lúcida etnografía sobre los modos de conocer la historia en Tapalpa. Con objetivos distintos a los de este trabajo, se ocupa allí de las distinciones entre el pueblo y las rancherías que entrañan complejas dinámicas étnicas. 
En el habla cotidiana de los lugareños, por supuesto, todas las alternativas son verdaderas, en cuanto se utilizan con fines comunicacionales para designar un grupo determinado de personas en el sistema social local. Las personas dicen y organizan sus pensamientos de muchas maneras y sus categorías, que no son otra cosa que representaciones sociales consolidadas por el uso, expresan diferentes dimensiones de la vida social y, en este sentido, a pesar de su posible ambigüedad o ambivalencia, son válidas. Pero para fines analíticos, la comunidad no puede ser un espejo de las expresiones usuales, sino que el investigador la define expresamente de acuerdo con sus objetivos de investigación, aunque considerando y tomando como referencia provisoria las categorías de uso local. En términos de investigación, se sugiere aquí que el truco pasa por distinguir de forma clara y adecuada los niveles y las unidades de análisis. Como ya se ha mencionado, seguir los nombres propios que designan las diferentes entidades sociales de contraste a escala local, es un primer paso y una tarea indispensable. Sin embargo, la situación revela un aspecto problemático de primer orden. Los procesos de identificación son siempre complejos y comportan diferentes instancias de autoadscripción, no excluyentes entre sí, que se activan de acuerdo con contextos de interacción particulares. Nada de esto tiene que ver con formulaciones esquizoides; más bien con categorías colectivas de identificación que, junto con los modos socialmente pertinentes de activación de esas categorías, son incorporadas en la subjetividad de los individuos durante los procesos de socialización, pasando a formar parte de su identidad personal. Un tapalpense, por ejemplo, de acuerdo con el contexto específico, puede sentirse miembro apasionado y legítimo del pueblo cabecera, experimentar la identificación de nivel parroquial, definirse como jalisciense y concebirse también como muy mexicano; si pertenece a alguna ranchería del municipio, lo hará saber en el momento oportuno. Algunos autores han abordado esta complejidad a través del concepto de identidades múltiples (Díaz Polanco, 2015, pp. 35-40) y es conocida la noción de identidades de guardarropa, de orientación más bien utilitaria y líquida (Bauman, 2003, pp. 210-212). El problema alcanza una expresión mayor cuando se trata de comunidades indígenas. Con demasiada frecuencia se ha supuesto que las identificaciones indígenas se oponen, si no excluyen, a la identidad nacional. La sospecha, sin embargo, no encuentra mayor respaldo en la observación empírica. La etnografía muestra tanto en la Norpatagonia como en la meseta purépecha que, si en la actualidad en muchos sentidos las identificaciones indígenas compiten con las nacionales, entre los purépechas y los mapuches es raro que operen como adscripciones identitarias excluyentes o negadoras de la identificación nacional. En varias conversaciones que se registraron con mapuches de la Línea Sur rionegrina, por ejemplo, surgió el tema de la guerra de Malvinas; invariablemente se los observó ofendidos con los ingleses - con quienes tienen además una densa historia local y regional-, sobre una clara base de identificación nacional. El equívoco parece originarse al confundir el manifiesto e intenso antagonismo político -en ocasiones ambiguo- de las comunidades indígenas respecto del estado nacional, algo que se verifica con claridad en contextos mapuches y purépechas, con los complejos procesos de identificación que admiten sin excluir, aunque no sin competencia, 
la identificación étnica con la nacional. A su vez, todo se entiende mejor al considerar el marco de las ideologías nacionalistas, mismas que históricamente han recurrido en su estrategia a la calificación del otro, en este caso indígena, como amenaza que socaba los procesos de construcción de la nacionalidad. De manera irónica y quizá cínica, entonces, son estas ideologías nacionalistas las que excluyen a las identificaciones indígenas. ${ }^{17}$

Por otra parte, si bien tienen fronteras que las definen y distinguen, las comunidades indígenas son sistemas abiertos en muchos sentidos. Como se ha afirmado, no sólo se insertan en sistemas políticos, sociales y económicos más amplios conformados a lo largo de la historia, sino que de hecho dependen de su articulación con diferentes entidades externas. En relación con el espacio, la palabra avecindado, usual en comunidades del occidente mexicano y de la Norpatagonia, expresa el asentamiento en el territorio comunitario de personas que en principio no forman parte de la comunidad. A su vez, la emigración prolongada e incluso definitiva de miembros de la comunidad no acarrea necesariamente la pérdida de membrecía, tal como revela la categoría hijo ausente, en el contexto mexicano. Más allá del notable caso de las comunidades citadinas del Valle Inferior rionegrino, con mayor frecuencia la pertenencia a la comunidad indígena se define a través del parentesco y la residencia; aun cuando la endogamia suele ser preferible y frecuente, muchas personas pasan a formar parte de la comunidad a través de las relaciones de alianza, aunque no siempre en forma plena. En los contextos que hemos estudiado en la Norpatagonia rural predomina la base ideológica patriarcal que prescribe la residencia posmarital masculina, lo que indica que la mujer ha de trasladarse a la casa del marido y por tanto también al territorio comunitario de éste. La regla no siempre se cumple y en ocasiones los hijos de este tipo de parejas de origen mixto cultivan membrecía en más de una comunidad. La organización política de muchas comunidades indígenas ilustra a la perfección la condición de sistema con límites pero abierto y articulado. Las comunidades tienen cierta autonomía política y con frecuencia establecen sus propias autoridades con métodos propios; una de las responsabilidades principales de estas autoridades es articular con agentes externos, muy en particular con otras comunidades y con el Estado en sus distintos niveles. Así, las comunidades mapuches de la Línea Sur designan además del lonko (cabeza), que tiene competencias de un poder ejecutivo, al werquén, una categoría del orden tradicional que viene a cumplir las tareas de un ministro de relaciones exteriores. Sobre la inclusión de las comunidades en el sistema económico más amplio, baste mencionar que la supuesta autosuficiencia que alguna vez se tuvo como característica distintiva de las comunidades campesinas (Aguirre Beltrán y Pozas Arciniega, 1981), es hoy poco menos que un mito. Todas las comunidades que el autor del presente artículo ha abordado en la Norpatagonia y en el occidente de México dependen, en alguna medida, de recursos externos. Las migraciones, intensas en ambas regiones, constituyen

17 Históricamente, estas ideologías han encarnado en el Estado. Tanto en México como en Argentina se han ejercido políticas de asimilación e invisibilización de las identificaciones indígenas. Si aún hay resabios de ello, hacia la década de 1980 se observa un giro hacia el respeto a la diversidad como guía nominal en las políticas de Estado (Serrano, 2019). 
procesos que también expresan con claridad las articulaciones comunitarias. Éstos son sólo algunos elementos orientados a demostrar que las fronteras comunitarias no son barreras infranqueables - si bien en ocasiones puedan alentarse diversas prácticas de cerramiento-, sino que ostentan distintos modos de apertura y articulación que de hecho hacen posible la existencia misma de las comunidades, tanto en el plano simbólico como en el de la subsistencia. En cualquier caso, de nuevo es responsabilidad de cada investigador identificar las instancias fundamentales de apertura y de articulación comunitarias a la luz de los propósitos de cada estudio. Con todo, se sugiere aquí que para fines de análisis las articulaciones deben examinarse cuando menos en dos niveles: a) vinculaciones con otras comunidades con las cuales hay cierta horizontalidad, es decir, comunidades vecinas o aquéllas con las que se comparten vínculos significativos forjados en el marco de proyectos de organización constituidos en clave étnica; y b) articulaciones asimétricas con referencia al Estado y sus diversas agencias así como, cada vez más, con grandes corporaciones que tienen el potencial de afectar de forma decisiva la situación de las comunidades (empresas forestales, mineras, entre otras), y también con organizaciones de la sociedad civil (ONG). Cada una de estas articulaciones, que comportan relaciones dinámicas y complejas, y que incluyen tanto momentos conflictivos como de sinergia y concurso de intereses, refuerzan el sentido de totalidad distintiva que experimentan de forma subjetiva los miembros de las comunidades indígenas. Lamentablemente no hay lugar aquí para profundizar en ello.

\section{Consideraciones finales}

A lo largo de este trabajo se ha pretendido, a través de ejemplos, circunloquios y aseveraciones directas, caracterizar la visión de los antropólogos sobre las comunidades. ¿Existe tal cosa? No, si se la entiende como mirada única y homogénea. En la actualidad, el debate sobre las comunidades en la antropología puede ser descrito en los términos que ya se han mencionado: una variedad de aproximaciones conceptuales, el uso habitual con referencia a problemáticas específicas y escenarios nacionales variopintos, pero todo bajo un común denominador: la persistente vigencia del concepto de comunidad (incluso los antropólogos reticentes al uso del término tienen el concepto como referencia ineludible) y la insistencia en tomar las comunidades como objeto de estudio predilecto. La impronta descriptiva perdura indeleble en las etnografías de comunidad, lo que no implica resignar inquietudes teóricas. Esto de ninguna manera puede ser considerado como un demérito, antes bien una virtud, ya que se trata de las pocas disciplinas -y seguro la principal- que basa sus reflexiones en un fuerte compromiso empírico, del cual difícilmente habrá de apartarse, que se apoya en la presencia intensiva en el campo y en la observación participante. Construye un tipo de conocimiento, podría decirse, que nace en la intimidad del fenómeno. Como aseverara Shinji Yamashita en la importante edición de Lins Ribeiro y Escobar sobre las Antropologías del mundo, los antropólogos permanecen comprometidos con la metodología de la observación participante 
etnográfica en relación con "una comunidad específica o una práctica cultural [...]. En otras palabras, la antropología es la única disciplina que todavía trata de formular teoría sociocultural a través de la observación participante en los micromundos sociales en que las personas viven" (Yamashita, 2009, pp. 70-71). En el corazón de la mirada antropológica, por lo demás heterogénea y cambiante, reposa una tradición peculiar de aproximación al fenómeno y de anudamiento en problemas empíricos y teóricos específicos. El compromiso empírico es la marca distintiva en la visión de los antropólogos. Lo que han dicho y tienen para decir sobre las comunidades llevan esa marca y sin duda pueden desde allí hacer aportaciones cruciales para la comprensión del fenómeno comunitario.

Con todo, en la actualidad las proposiciones teóricas generadas en la antropología no participan lo suficiente en las discusiones más sonadas sobre las comunidades, aunque es cierto que en algunos países tienen fuerte incidencia en las políticas indigenistas y en las definiciones legislativas. Es evidente, no obstante, que la teorización antropológica de inspiración empírica podría enriquecer de manera significativa el debate dominado, hoy por hoy, por la filosofía política y la sociología teórica. Además de la originalidad de los conocimientos que genera a partir de su particular adhesión al escrutinio empírico, y a la reflexión de base inductiva, ofrece la inestimable posibilidad de contrastar en el terreno las grandes propuestas teóricas que se gestan en la filosofía y en la sociología. Por ejemplo, los antropólogos podrían revisar a través de la observación etnográfica sistemática las estimulantes ideas de Roberto Esposito (2003) acerca de las relaciones comunitarias basadas en la obligación de dar y, de hecho, también su inquietante propuesta sobre la modernidad como proyecto inmunitario (es dudoso que esto se haya siquiera intentado).

La propuesta que se ha presentado aquí distingue tres ejes que deben entenderse como vías para abordar, examinar y analizar la comunidad, la cual es concebida decisivamente como fenómeno complejo. El primero de ellos constituye sobre todo una advertencia contra los peligros de la aproximación intuitiva y de toda codificación reduccionista. Ya como objeto de estudio, la comunidad es siempre un problema cuya definición corresponde al investigador, problema que conjuga en una misma trama elementos del fenómeno y operaciones de conceptualización. El segundo impugna la aparente inmutabilidad de las comunidades - algo asumido con recurrencia, ya sea en términos absolutos, de grado o como tendencia- y aboga por la necesidad de discernirlas a la luz de procesos históricos y como proyectos de futuro. De modo previsible, esto último será lo que más ha de llamar la atención de los especialistas. El tercer eje se enfoca en el sistema de relaciones que da lugar y permite explicar la comunidad. Entre otras cosas, esto conlleva indagar la delimitación simbólica de la comunidad y las articulaciones internas y externas que la constituyen. El esquema propuesto arraiga con nitidez en la tradición antropológica. Se apoya en la propia experiencia etnográfica y alude fundamentalmente, como se ha hecho explícito, a contextos indígenas y campesinos. Aunque se presume su utilidad en muchos otros escenarios, su pertinencia y eficacia deberán probarse en cada caso. 


\section{Referencias}

Aguirre Beltrán, G. (1990). Crítica antropológica. Hombres e ideas, contribuciones al estudio del pensamiento social en México. México: Fondo de Cultura Económica (FCE), Instituto Nacional Indigenista (INI), Universidad Veracruzana y Gobierno de Veracruz.

Aguirre Beltrán, G., y Pozas Arciniega, R. (1981). La política indigenista en México. Métodos y resultados, t. II. México: INI y Secretaría de Educación Pública.

Anderson, B. (1991). Imagined Communities: Reflections on the Origin and Spread of Nationalism. Londres y Nueva York: Verso.

Barth, F. (1976). Los grupos étnicos y sus fronteras. México: FCE.

Basch, L., Schiller, N., y Blanc, C. (1994). Nations Unbound: Transnational Projects, Postcolonial Predicaments, and Deterritorialized Nation-States. Londres: Routledge.

Bauman, Z. (2003). Modernidad líquida. México: FCE.

Bauman, Z. (2006). Comunidad. En busca de seguridad en un mundo hostil. Madrid: Siglo XXI.

Blackshaw, T. (2010). Key Concepts in Community Studies. Londres: Sage.

Boccara, G. (ed.). (2002). Colonización, resistencia y mestizaje en las Américas (siglos XVI-XX). Quito: Abya-Yala.

Bonfil Batalla, G. (1995). El concepto de indio en América: una categoría de la situación colonial. En L. Odena Güemes (comp.), Obras escogidas de Guillermo Bonfil (pp. 337-357). México: INI-INAH-DGCP-Conaculta-Fifonafe.

Brow, J. (1990). Notas sobre comunidad, hegemonía y los usos del pasado. Anthropological Quarterly, 63 (1), 1-6.

Caso, A. (1996 [1948]). Definición del indio y lo indio. En Autor, Homenaje a Alfonso Caso. Obras escogidas (pp. 331-338). México: Patronato para el Fomento de Actividades Culturales y de Asistencia Social a las Comunidades Indígenas, A. C.

Cohen, A. (1985). The Symbolic Construction of Community. Londres y Nueva York: Tavistock.

Crow, G., y Allan, G. (1994). Community Life: An Introduction to Local Social Relations. Londres: Harvester Wheatsheaf.

Delgado, M. (2006). Espacio público y comunidad. De la verdad comunitaria a la comunicación generalizada. En Lisbona Guillén (ed.), La comunidad a debate. Reflexiones sobre el concepto de comunidad en el México contemporáneo (pp. 39-59). Zamora: El Colegio de Michoacán (COLMICH).

Díaz Polanco, H. (1995). Autonomía, territorialidad y comunidad indígena. La nueva legislación agraria en México. En V. Chenaut y T. Sierra (coords.), Pueblos indígenas ante el derecho (pp. 231-60). México: CEMCA-CIESAS.

Díaz Polanco, H. (2015). El jardín de las identidades. La comunidad y el poder. México: Orfila.

Esposito, R. (2003). Communitas. Origen y destino de la comunidad. Buenos Aires: Amorrortu. 
Garibay Orozco, C. (2008). Comunalismos y liberalismos campesinos. Identidad comunitaria, empresa social forestal y poder corporado en el México contemporáneo. Zamora: COLMICH.

Giménez, G. (1997). Materiales para una teoría de las identidades sociales. Frontera norte, 9(18), 9-28.

Giménez, G. (2001). Cultura, territorio y migraciones. Aproximaciones teóricas. Alteridades, 22, 5-14.

Gorilek, A. (2008). La aldea en la ciudad. Ecos urbanos de un debate antropológico. Revista del Museo de Antropología, 1(1), 73-96.

Gossiaux, F. (1996). Comunidad. En P. Bonte y M. Izard (eds.), Diccionario de etnología y antropología (pp. 182-184). Madrid: Akal.

Groppo, A. (2011). Tres versiones contemporáneas de la comunidad: hacia una teoría política post-fundacionalista. Revista de filosofía y teoría política, (42), 49-68.

Haesbaert, R. (2011). El mito de la desterritorialización: del "fin de los territorios" a la multiterritorialidad. México: Siglo XXI.

Honneth, A. (1999). Comunidad. Esbozo de una historia conceptual. Isegoría, (20), 5-15.

Lewis, O. (1951). Life in American Village: Tepoztlan Reestudied. Champaign: University of Illinois Press. (Traducción en español: Tepoztlán, un pueblo de México. México: J. Moritz, 1960).

Lisbona Guillén, M. (ed.). (2006). La comunidad a debate. Reflexiones sobre el concepto de comunidad en el México contemporáneo. Zamora: COLMICH.

Marinis, P., de. (2010). La comunidad según Max Weber: desde el tipo ideal de la Vergemeinschaftung hasta la comunidad de los combatientes. Papeles del CEIC (1), 1-36.

Marinis, P., de. (ed.). (2012). Comunidad: estudios de teoría sociológica. Buenos Aires: Prometeo Libros.

McMillan, D., y Chavis, D. (1986). Sense of community: A definition and theory. Journal of Community Psychology, 14(1), 6-23.

Nancy, J.-L. (2000). La comunidad inoperante. Santiago de Chile: Universidad Arcis.

Nisbet, R. (2003). La formación del pensamiento sociológico. Buenos Aires: Amorrortu.

Paredes Martínez, C. (2017). Al tañer de las campanas. Los pueblos indígenas del antiguo Michoacán en la época colonial. México: CIESAS.

Portes, A. (1997). Globalization from Below: The Rise of Transnational Communities. Princeton: Princeton University.

Quijano, A. (2000). Colonialidad del poder, eurocentrismo y América Latina. En E. Lander (ed.), Colonialidad del saber, eurocentrismo y ciencias sociales (pp. 201-146). Buenos Aires: Clacso.

Redfield, R. (1941). The Folk Culture of Yucatan. Chicago: University of Chicago Press.

Redfield, R. (1955). The Little Community: Viewpoints for the Study of a Human Whole. Chicago: University of Chicago Press. 
Rouse, R. (1991). Mexican Migration and the Social Space of Postmodernism. Diaspora A Journal of Transnational Studies, 1(1), 8-23. doi: 10.1353/ dsp.1991.0011

Sarason, S. (1974). The Psychological Sense of Community: Prospects for a Community Psychology. San Francisco: Jossey-Bass.

Serrano, J. (2002). La dimensión cultural de las remesas: los tapalpenses y su comunidad transnacional (tesis de maestría). Maestría en Antropología Social, Centro de Investigaciones y Estudios de Antropología Social-Occidente. Guadalajara: CIESAS.

Serrano, J. (2006). El sueño mexicano. El retorno imaginado en las migraciones internacionales de Tapalpa y Tlacotalpan (tesis doctoral). Doctorado en Ciencias Sociales, Centro de Investigaciones y Estudios de Antropología Social-Occidente. Guadalajara: CIESAS.

Serrano, J. (2019). Comunidad, identidad y preexistencia indígena en la legislación argentina: suspicacias antropológicas. Manuscrito inédito.

Serrano, J. (2020a). De gesta a genocidio. La disputa por las concepciones acerca de la Conquista del Desierto. En Ma. T. Varela y R. Tarifeño (comps.), VIII Jornadas de Historia de la Patagonia. "La Patagonia en el escenario nacional: miradas sobre el pasado, presente y futuro” (pp. 17-33). Viedma: CURZA-UNCOMA.

Serrano, J. (2020b). Las comunidades indígenas en el Valle Inferior del río Negro: aproximación teórica, interrogantes y resultados preliminares de investigación. Manuscrito inédito.

Stack, T. (2012). Knowing History in Mexico: An Ethnography of Citizenship. Albuquerque: University of New Mexico Press.

Warman, A. (2003). Los indios mexicanos en el umbral del milenio. México: FCE.

Wegner, P. E. (2002). Imaginary Communities: Utopia, the Nation, and the Spatial Histories of Modernity. Londres: University of California Press.

Wolf, E. (1955). Types of Latin American Peasantry: A Preliminary Discussion. American Anthropologist, 57(3), 452-471.

Wolf, E. (1957). Closed Corporate Peasant Communities in Mesoamerica and Central Java. Southwestern Journal of Anthropology, 13(1), 1-18.

Wolf, E. (1990). Relaciones de parentesco, de amistad y de patronazgo en las sociedades complejas. México: CIESAS, Universidad Autónoma Metropolitana (UAM) y Universidad Iberoamericana (UIA).

Yamashita, S. (2009). Reconfigurando la antropología: una visión desde el Japón. En G. Lins Ribeiro y A. Escobar (eds.), Antropologías del mundo. Transformaciones disciplinarias dentro de sistemas de poder (pp. 57-80). México: CIESAS, UAM y UIA.

Zárate Hernández, E. (2011). Comunidad, reformas liberales y emergencia del indígena moderno: Pueblos de la meseta Purépecha (1869-1904). Relaciones. Estudios de historia y sociedad, 32(125), 17-52.

Zolla, C., y Zolla, E. (2004). Los pueblos indígenas de México: 100 preguntas. México: UNAM. 